\title{
TOBÍO, O XORNALISTA EN ACCIÓN
}

\section{Xan Carballa}

Xornalista e editor

DOI: 10.17075/ltgtx.2020.005 

Reproducindo hai uns anos o álbum fotográfico de Lois Tobío, dei coa imaxe do xornalista no medio do batifondo dunha redacción. En Uruguai o exiliado atopara acomodo temporal no xornal El Día de Montevideo, na altura o medio de

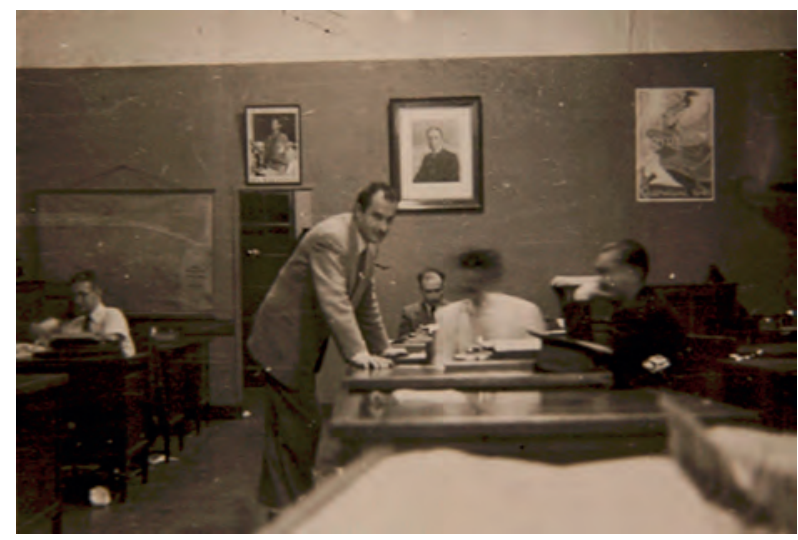
comunicación máis importante do país, fundado por José Batlle y Ordóñez, quen foi dúas veces presidente da República Oriental. Tobío traballou a soldo e tempo completo como redactor permanente entre 1944 e 1947, aínda que xa anteriormente exercía de colaborador ocasional do seu importante suplemento. Podemos imaxinar que un concentrado Tobío estaría escribindo á máquina algúns dos seus numerosos artigos de política internacional, especialización que en boa lóxica foi unha das súas permanentes responsabilidades, pero tamén tocaba outros xéneros. Así describe el mesmo aquel tempo, «tiña como principal tarefa facer entrevistas a personalidades estranxeiras que chegaban ao país e uruguaios que voltaban dalgunha misión no estranxeiro, ademais dos artigos que xa viña publicando en que comentaba a política internacional. Tamén escribía de cando en cando algunha nota para a sección de editoriais, que eran no noso xornal breves e substanciosos, dicindo en poucas palabras o que había que dicir e non como os que se ven agora nos 
xornais españois, longos, pesados, reiterativos e arrevesados. A min paréceme que hai un desaxuste entre ese estilo xornalístico e o mundo de hoxe, no que a xente non anda sobrada de tempo para ler tan longos parrafeos. Non sei se isto será un resto da retórica do franquismo pero o certo é que nos tempos inmediatamente anteriores á Guerra Civil o xornalismo español caracterizábase por unha escrita clara, concisa e precisa do que era bo expoñente El Sol».

Todo isto cóntanolo Tobío no seu formidable libro de memorias, As décadas de T. L., que se poden ler como unha extensa reportaxe, chea de reflexións, información persoal... pero tamén coa aguda visión dun home que se viu obrigado, coma tantos da súa xeración, a forxar a vida no cruxol máis fervente do século XX, o que abrangue dúas guerras mundiais, un golpe militar, unha guerra civil e unha ditadura ferreña de 40 anos, con apenas unha raiola de esperanza republicana e de emancipación nacional para Galiza (1931-1936), para despois conducirse polo continente americano como un exiliado até remansar en Montevideo.

Estritamente a vida profesional como xornalista a tempo completo pertence a este período en El Día, pero coma outras moitas xentes da súa xeración, Tobío tiña nos xornais un vehículo posible de desenvolvemento das súas ideas e posicións, tamén concibido como lugar de encontro e debate. Cóntanos de cando vivía en Compostela, «había en Santiago tres xornais, un da mañá, o Diario de Galicia, católico, e dous de tarde independentes, El Compostelano e El Eco de Santiago. No primeiro estaba de redactor-xefe Xohán Xesús González, que fora canteiro (e falaba o verbo dos arxinas) e que, polo seu esforzo autodidacta, chegará a ser xornalista e mesmo estudará por libre a carreira de dereito [...]. De cando en cando iamos á redacción do xornal, que se achaba na Porta da Mámoa, e alí, no seu despacho, que estaba a carón das máquinas porque o local era pequeno, faciamos tertulia comentando as novas do día». E retrata tamén como era a fame coa que buscaban nos xornais, «devorabamos a prensa que estaba contra a ditadura, case toda, pero principalmente El Sol, os artigos de Moreno Villa e Ortega, as "Charlas al sol” de Heliófilo, e teimábamos descifrar o sens dos "Dibujos de almohadón” de Bagaría; e todo isto comentábamos en claustros e cafés». 
Acaso envelenado pola tensión creativa das redaccións ou polo cheiro aditivo do chumbo das linotipias, Tobío describe no seu percorrido biográfico as diferentes ocasións que tivo de ligar parte do seu empeño vital aos medios de comunicación. Por exemplo, cando vivía en Berlín ampliando estudos en 1929, «o Armesto levaba algún tempo en Berlín de onde mandara, nun principio, crónicas para El Pueblo Gallego, pero un día, segundo me contou, ocorréuselle enviar unha a La Vanguardia de Barcelona sobre un tema de actualidade alemá, co pseudónimo Augusto Assía, que tomara dun personaxe de Pío Baroja, e tanto lles gustaran os artigos aos cataláns que lle contestaron que podía seguir a lles mandar traballos como aquel pois non tiñan correspondente en Berlín [...]. Pola miña parte, e a suxestión de Felipe, tentarei máis adiante repetir o xogo que a el tan ben lle saíra, e fíxeno co Heraldo de Madrid sen que tan sequera me contestaran».

En As décadas de T. L., o autor apunta con detalle moitas vicisitudes e aspectos da vida da redacción de El Día e tamén do xornalismo e a prensa no Uruguai. Son interesantes porque sintetizan coas artes do oficio de xornalista unha chea de datos políticos e referencias das persoas coas que compartiu mesa e tamén sitúan as tensións coas que se conducía a política no final da II Guerra Mundial e no limiar da Guerra Fría, en particular en América as relacións cos Estados Unidos. Paga a pena transcribir a delgada liña que non era posible atravesar.

Dinos Tobío:

[...] como eu publicaba no xornal artigos e comentarios de política internacional, puiden decatarme da actitude que alí seguían verbo diso. Non se podía dicir cousa ningunha que supuxese censura ou crítica cara os ingleses e norteamericanos máis que fose lene ou matizada. Todo o que eles facían e dicían estaba ben e era merecente de loanza por intelixente e xusto. E como todo orixinal político, antes de pasar ao prelo, tiña que ser lido na dirección, se o director ou os seus asesores non o xulgaban axeitado, deixábase nunha bandexa de artigos «retenidos», que viña ser un eufemismo para «desbotados», e alí morría. Lémbrome que unha vez en que unha nota miña sufrira esa condena expliquei que todos os dados que contiña foran tomados de fontes norteamericanas, máis ca nada 
do Time, e que os xuízos que facía o semanario ianqui eran aínda máis duros do que os meus. E a resposta foi que iso non tiña nada que ver, que alá podían facer esas críticas pero fóra dos Estados Unidos non porque viña ser propaganda contra a causa dos aliados que había que asumir por todos os medios. E que non era a causa dos aliados como tal a que eles dicían defender demóstrao o feito de que esa actitude soamente se daba cara Inglaterra e os Estados Unidos e tamén cara Francia ata a rendición pero non cara á URSS; por este motivo tamén algunha nota miña sería rexeitada.

No ano 1947 finalizará a relación de tempo completo con El Día e por tanto a plena dedicación ao xornalismo, que coincide co final da cuarta década de vida de Lois Tobío, aínda que manterá o cordón umbilical mentres vive no Uruguai con diferentes colaboracións no Suplemento Dominical, sobre arte, literatura, historia e viaxes entre outros asuntos.

Continuará atendendo aquí e alá peticións de colaboracións e débese sinalar en letra dourada de molde que Tobío aparece en 1950, xunto a Alfredo Somoza, Xesús Canabal, Manuel Meilán, Pedro Couceiro, Manuel Leiras e Antón Crestar, entre os fundadores dunha audición radiofónica histórica, Sempre en Galiza, que se comezou a emitir en galego os domingos ás nove e media da mañá nas ondas montevideanas de Radio Carve, unha das estacións máis importantes do país. Concibido como un programa "galeguista, republicano e cultural», é o máis antigo da radiodifusión en galego, aínda hoxe acollido nas ondas de Radio Oriental, e mantendo ao longo do tempo a mesma voz e mensaxe de entrada e saída na voz de Manuel Meilán, «Bos días, aquí Sempre en Galiza», baixo o fondo da Muiñeira de Chantada.

\section{O ARQUIVO TOBÍO}

Agrupar en detalle todo o patrimonio de escritos de Tobío non é doado pero si posible. A súa filla Constanza tennos facilitado algúns artigos para podermos ver 
como era aquela prensa uruguaia dos 50, que aínda está por dixitalizar. Pero seu pai basicamente gardou páxinas relacionadas con Galicia, aínda que xa está feito un baleirado de contidos e indexados os artigos que levan a súa sinatura nas súas décadas xornalísticas e non sería complicado reunir nun fondo dixital en acceso público toda a obra do Tobío xornalista.

Para non ficar con sabor da ausencia, escollemos reproducir un anaco dunha das reportaxes que escribiu para El Día en maio de 1950. Pola actualidade tomei o referido á cerámica de Sargadelos, escrito denantes da refundación de Luís Seoane e Isaac Díaz Pardo e referido ao histórico esplendor da marca da man de Antonio Raimundo Ibáñez.

\section{La Novela de Sargadelos}

LOIS TOBÍO

Tal vez en algún hogar uruguayo de ascendencia gallega se conserva todavía, como recuerdo de los abuelos, alguna pieza de loza o «china opaca» de Sargadelos. Será una figurita delicada o grotesca, un tintero o escribanía, una sopera o fuente monumentales, un florero o un aguamanil, o sencillamente un plato, con ornamentación pintada a mano o estampada, en uno o varios colores. Los colores en estas piezas son de fina, agradable tonalidad, y a veces tienen un delicioso esfumado. Los dibujos son muy variados, predominan las flores y los paisajes fantásticos, chinescos o románticos. En otros casos, aparecen vistas de ciudades o escenas del Quijote. Las más modernas de estas creaciones tienen casi cien años y con frecuencia se mantienen en buen estado. El material de que están hechas es noble, apretado, resistente: a veces ostenta esa caprichosa red del cuarteado o «craquelé» que acrecienta su belleza.

En las viejas casas de mi ciudad natal, que no queda lejos de donde estuvo la fábrica, solía yo ver, en mi infancia, esos ejemplares llenos del encanto de las cosas familiares y amadas. ¡Cómo me divertían aquellos Mambrús cómicamente sentados, con su casa azul y su sombrero de candil! A los lados de la pequeña imagen, que estaba cubierta de un 
fanal, sobre la cómoda, había dos historiados floreros sargadeleños de varios brazos; por la cocina rodaban, recios vencedores del trasteo de muchos decenios, varios platos de dibujos azules. No se les daba entonces a esos objetos mayor importancia; se los trataba con la llaneza con que se trata a antiguos conocidos, a parientes; se les quería por ser viejos en la casa, pero no se pensaba que pudiesen tener un valor cotizable. Ahora, en cambio, coleccionistas y museos se los disputan a porfía. Hasta los más sencillos se exhiben en vitrinas o se cuelgan de las paredes. Ya no juegan con ellos los chiquillos, ni vienen a la mesa, ni arriesgan su vida en las manipulaciones del fregado. Gozan de la consideración de una joya, de un objeto de arte.

Y la merecen. La merecen, a menudo, por si mismas, porque son lindas muestras de un arte unas veces lleno de gracia ingenua y popular y otras refinado y elegante. Y la merecen, además, por ser resto y testimonio de una interesante manufactura gallega creada en un lugar recóndito, por el genio de un hombre excepcional, curioso exponente del espíritu progresista y emprendedor del siglo XVIII. No se sabe bien cómo aquel afán renovador y creador vino a infundirse en un hidalguillo lugareño y hacerlo soñar con atrevidas aventuras económicas. El primer impulso debió ser obra de ciertas lecturas no raras entonces, sobre las posibilidades que ofrecían los recursos del país. Más tarde debió fortalecer aquel impulso el contacto con hombres competentes y animosos a los que acuciaba un mismo anhelo. Pero todos esos estímulos hubiesen sido nada de no haber encontrado terreno propicio en el carácter ambicioso y resuelto del joven.

Lo que se proponía hacer [Antonio Raimundo Ibáñez], y lo que al cabo hizo, chocaba bruscamente con el ambiente agrario y tradicionalista de la tierra en que se había criado y en que iba a desarrollar sus proyectos. Hubo de vencer muchos obstáculos y hubo de lesionar intereses. En nada reparaba; iba adelante con paso firme; cuando precisaba ser duro lo era al extremo. Por eso se hizo odioso. Era el antagonismo entre dos mundos, entre dos sistemas económicos y sociales, el uno con todo el peso de la tradición y de la masa, el otro con toda la osadía conquistadora de la mocedad. Y ese antagonismo estalló al fin en violencia. El industrialismo, que tanto haría crecer la riqueza, adviene imponiendo sacrificios. La vida de este campeón de la nueva época termina trágicamente, pero su obra sobrevive por más de sesenta años. En conjunto, la historia de la empresa Sargadelos tiene no poco de novela. Una novela fascinadora en que hay episodios de todo jaez. [...] 